\title{
LOS ESTUDIOS SOBRE LAS HACIENDAS CONCEJILES ESPAÑOLAS EN LA EDAD MEDIA
}

\author{
ANTONio COllantes de TeRÁN SÁNCHEZ
}

\author{
SUMARIO
}

1. Fuentes. - 2. Estudios

La proliferación de trabajos sobre la hacienda y la fiscalidad municipales en la Edad Media durante las dos últimas décadas ha venido a romper la prolongada ausencia de este tema de los intereses de la historiografía peninsular, apenas alterada por la aparición esporádica de algún artículo o de algún trabajo de mayor enjundia, como los de Carande y Font Rius, por citar algunos '. En este sentido, es sintomático que con la proliferación de congresos, coloquios, simposios, jornadas, etc., ya sean internacionales, nacionales, regionales, comarcales o locales, que se han venido celebrando en los últimos años en España ninguno se haya dedicado expresamente al tema ${ }^{2}$, aunque sí se han presentado comunicaciones sueltas en otros de temática diversa. Ante dicha reciente proliferación, nada mejor que un monográfico dedicado a la fiscalidad

1 Es cierto que las cosas no estaban mucho mejor en el resto de Europa, como se deduce de trabajos publicados en la década de los sesenta: Finances et comptabilité urbaines du XIIle au XVIe siècle, "Colloque International Blankenberge», Pro Civitate, Bruxelles, 1964; L'impôt dans le cadre de la ville et de l'etat, "Colloque International de Span", Pro Civitate, Bruxelles, 1966; Jean FAVIER, L'bistoire administrative et financière du Moyen Age depuis dix ans, "Bibliothèque de l'École des Chartes», CXXVI (1968), pp. 427-503.

${ }^{2}$ Las jornadas dedicadas a este tema por el Instituto de Estudios Baleáricos en 1987 estuvieron centradas en la Edad Moderna (Fiscalitat estatal $i$ bisenda local (ss. XVI-XIX): Funcionament $i$ repercussions socials, Institut d'Estudis Baleàrics, Palma de Mallorca, 1988). 
para presentar esta bibliografía, con el fin de ver cuales han sido las líneas de investigación.

En primer lugar destaca la ausencia de obras de síntesis, sobre todo recientes. Esto no quiere decir que no existan algunas visiones de conjunto, algunas aproximaciones más o menos globales, como las realizadas por José María Font Rius y Max Turull para Cataluña, o por mí para Andalucía '. No conozco nada similar para el resto de la Corona de Castilla, ni para los reinos de Aragón, Valencia y Navarra ${ }^{4}$. También se puede encontrar algún capítulo o apartado dedicado a estas cuestiones en obras de carácter general sobre las ciudades o el fenómeno urbano. Una de las primeras fue la de Sacristán en el siglo pasado, a las que se suman en el actual las de Carlé y Gautier-Dálche. Las dos primeras, las de Sacristán y Carlé, poseen un enfoque institucionalista. Por otro lado, las de Carlé y Gautier-Dalche, publicadas en la década de los sesenta, se centran en la Plena Edad Media, por lo que todo el período bajomedieval,

' José María FONT RIUS, Organos y funcionarios de la administración económica en las principales localidades de Cataluña, "Finances et comptabilité», pp. 257-277; La administración financiera en los municipios medievalescatalanes, «Historia de la Hacienda Española. Épocas Antigua y Medieval. Homenaje al Profesor García de Valdeavellano", Madrid, 1982, pp. 193-231; Max TURULL, Finances i fiscalitat municipals a Catalunya durant la Baixa Edat Mitjana, "L'Avenç», 139 (1990), pp. 60-65; Antonio COllaNTES DE TERÁN SÁNCHEZ, Ciudades y Fiscalidad, "Las ciudades andaluzas (siglos XIII-XVI). Actas del VI Coloquio Internacional de Historia Medieval de Andalucía», Universidad de Málaga, Málaga, 1991, pp. 129-149; previamente había realizado una primera aproximación en el tomo III de la Historia de Andalucia, Madrid, Planeta, 1980, pp. 308-314. José María FONT RIUS también ofreció unos apuntes sobre el conjunto de los reinos españoles en Las instituciones administrativas y judiciales de las ciudades en la España medieval, presentado a la Sociedad Jean Bodin y reeditado en "Anales de la Universidad de Valencia», XXVI (1952-1953), pp. 91-118.

${ }^{4}$ Basta repasar los contenidos de estados de cuestión o de reuniones científicas que han tenido como tema central a las ciudades, para confirmar esta realidad. Como ejemplo, en el congreso celebrado en León en 1989 centrado en los concejos y las ciudades, y a pesar de su fuerte carga institucionalista y social, dos ámbitos que entroncan directamente con la hacienda y la fiscalidad, apenas algunos párrafos en dos o tres de las ponencias tocan el tema (Concejos y ciudades en la Edad Media Hispánica. "II Congreso de Estudios Medievales», Fundación Sánchez Albornoz, León, 1990). Otro tanto se puede decir de los artículos que aparecen en el monográfico dedicado al régimen municipal en la Corona de Aragón por la revista «Estudis Baleàrics», 31 (1988), así como en los estados de cuestión y revisiones de líneas de investigación, donde la alusión a este tema es marginal, aunque lo normal es que no exista ninguna referencia, como se puede comprobar en "Studia Historica», VI (1988), y en Cristina Segura Graíño, ed., Presente y futuro de la Historia Medieval en España, "Actas de las I Jornadas sobre la investigación medieval en las Comunidades Autónomas», Universidad Complutense, Madrid, 1990. 
para el que se dispone de mucha más información, queda fuera de sus campos respectivos de observación '.

Frente a esta ausencia de síntesis, encontramos una generalizada presencia de trabajos de carácter local o puntual, enfocados hacia el estudio de una ciudad o villa, hacia el análisis de los propios o de algunas rentas, etc. Dentro de esta abundancia de aportaciones, también se observan notables desigualdades, entre las distintas entidades políticas. Ante todo resalta el hecho de que la mayor parte de los trabajos corresponden al ámbito de la Corona de Castilla, mientras que es muy pobre la referida a los reinos de la Corona de Aragón y de Navarra ${ }^{6}$. Dentro de aquélla sobresale el caso de Murcia, con veinte títulos; casi ninguno de los medievalistas de esta ciudad se ha sustraido a la atracción de publicar algo sobre el tema. Le sigue en importancia Burgos. Es posible que en dichas desigualdades tenga bastante que ver la documentación conservada. Las dos ciudades mencionadas, junto con Sevilla, son las que, dentro de la Corona de Castilla, parecen conservar los mejores fondos documentales de esta naturaleza, que se remontan a las últimas décadas del siglo XIV. Entre los centros urbanos de menor importancia destaca la documentación de Piedrahita.

\section{FUENTES}

Son muchos los documentos que, como piezas justificativas, se han venido publicando en apéndices de numerosas obras que tienen como tema el que aquí nos ocupa u otros, lo que hace imposible referirme a ellos. Valga como ejemplo la publicación de los documentos por los que los monarcas iban concedidendo propios o rentas a los diferentes concejos, una vez que habían sido conquistadas las respectivas ciudades y se iniciaba su repoblación. Aquí me centraré en colecciones de fuentes, en las que la hacienda o la fiscalidad tengan un cierto

' Antonio SaCRISTÁn y MARTínez, Municipalidades de Castilla y León, Madrid, 1877 (reed. Instituto de Estudios de Administración Local, Madrid, 1981); María del Carmen CARLÉ, Del concejo medieval castellano-leonés, Buenos Aires, Instituto de Historia de España, 1968; Jean GAUTIER-DALCHÉ, Historia urbana de León y Castilla en la Edad Media (siglos IX-XIIl, Madrid, Siglo XXI, 1979.

- Aparte de la escasa bibliografía que aparece en este artículo, es esclarecedor de la tendencia las prácticamente nulas alusiones al tema en los informes presentados por Angel J. Martín Duque, José Angel Sesma Muñoz, Carmen Batlle, Joan J. Busqueta, Coral Cuadrada y José Hinojosa Montalvo a las "Jornadas sobre la investigación medieval en las Comunidades Autónomas» (C. Segura Graíño, ed.: Presente y futuro). 
protagonismo, y en trabajos sobre metodología, análisis y estudios de documentos hacendísticos o fiscales.

La escasa importancia atribuida durante décadas a los fondos de carácter económico, unido a que los de naturaleza contable propiamente dicha se han perdido en la mayor parte de los archivos, y en los que han tenido la fortuna de conservar algo, no se remontan más allá de finales del siglo XIV, período al que tampoco se prestaba mucha atención por los medievalistas de épocas pasadas a la hora de publicar textos, todo ésto ha hecho que en las grandes colecciones documentales los referidos a las haciendas concejiles en general hayan brillado por su ausencia. En los últimos años están viendo la luz colecciones locales, y en éllas ya tienen cabida dichas fuentes, transcribiéndose cuentas de propios y otros documentos '; también hay que reseñar las realizadas por reinados, ya comprendan a todo el reino o a algunos de sus territorios ${ }^{8}$.

Dentro de este apartado hay que mencionar los fueros y las ordenanzas concejiles, muchas de las cuales se recopilaron y, en ocasiones, se publicaron en el siglo XVI. En los primeros se pueden encontrar los balbuceos de la fiscalidad local y de su gestión, en las segundas es normal que aparezcan varios capítulos

7 Entre el elevado número de obras, podemos citar como representativas de distintos períodos las siguientes: Tomás GONZÁlEZ, Colección de privilegios fiscales de Castilla, VI, Madrid, 1830-1833; VVAA, Libros de acuerdos del concejo madrileño, 4 vols., Madrid, 1932-1982; Actes municipals, 1358-1360, Tarragona, Ajuntament, 1983; Concepción HidAlgo De Cisneros Amestoy, Elena LARGaCHA RUBiO, Araceli LORENTE RUigómeZ, Adela MARTínez LaHIDALGa, Libro de decretos y actas de Portugalete (14101516), San Sebastián, 1988. La excepcional Colección de Documentos Históricos del Reino de Murcia, dirigida por Juan Torres Fontes, Academia Alfonso X el Sabio, Murcia, iniciada en 1963, con nueve tomos publicados. Carmelo LUIS LÓPEZ, Colección Documental del Archivo Municipal de Piedrabita (1372-1549), Avila, Institución Gran Duque de Alba y Caja de Ahorros, 1987; Angel Barrios GarCía, José María MONSAlvo ANTón, Gregoria del SER QuiJANo, Documentación Medieval del Archivo Municipal de Ciudad Rodrigo, Salamanca, Diputación Provincial, 1988; María Dolores García Oliva, Documentación Histórica del Archivo Municipal de Cáceres (1475-1504), Cáceres, Diputación Provincial, 1988; Javier ENRÍQUeZ FeRnÁNDEZ, Colección Documental de la villa de Plencia (1299-1516), San Sebastián, 1988; Carlos Laliena CORBERA, Documentos municipales de Huesca, 1100-1350, Huesca, Ayuntamiento, 1988; José RODRíGUEz MOLINA, Colección Diplomática de Baeza (siglos XIIl-XV), Jaén, 1983; Emiliano GoNZÁLEZ DíEZ, Colección diplomática del concejo de Burgos (884-1369), Burgos, Instituto de Estudios Castellanos, 1984.

${ }^{8}$ Entre las publicaciones recientes se encuentran las de Julio GoNZÁLEZ, Reinado y diplomas de Fernando III, 3 vols., Córdoba, Monte de Piedad y Caja de Ahorros, 1980-1986; y la de Manuel GonZÁleZ JimÉneZ, ed., Diplomatario andaluz de Alfonso X, Sevilla, Monte de Piedad de Huelva y Sevilla, 1991. 
dedicados a los propios y su administración, a las instituciones concejiles encargadas de la gestión y control de ingresos y gastos, etc. '.

Por lo que se refiere a trabajos de tipo metodolígico y de descripción de contenido de fuentes, hay varios que tocan a las haciendas y a la fiscalidad, que pueden ser de utilidad ".

\section{ESTUDIOS}

Entrando ya en los estudios sobre hacienda y fiscalidad, y una vez reseñados más arriba los que presentan visiones de conjunto, habría que empezar por las monografías relativas a ciudades concretas en las cuales se analizan dichos temas. En este contexto, el punto de partida hay que situarlo en Sevilla, fortaleza y mercado de Ramón Carande Tovar, publicado en $1925^{\text {". Sin }}$ embargo, habría que esperar años para que el ejemplo cundiese.

Como había ocurrido con tantos otros aspecto de la realidad histórica, los primeros pasos se dieron a través de los estudios institucionalistas. Ahora bien, mientras que algunos de los más antiguos y de los recientes se circunscriben al análisis estrictamente jurídico de la organización concejil, y dentro de ella a las

9 Una relación exhaustiva de fueros y la bibliografía correspondiente en Ana María BARrero García y María Luz ALONSO MARTín, Textos de Derecho local español en la Edad Media. Catálogo de fueros y costums municipales, Madrid, 1989. Para las ordenanzas Miguel Angel LADERO QUESADA e Isabel GALÁN PARRA, Las ordenanzas locales en la Corona de Castilla como fuente bistórica y tema de investigación (siglos XIII al XVIII), "Anales de la Universidad de Alicante, Historia Medieval», 1 (1982), pp. 221-243, con posterioridad se han publicado más ordenanzas. También el trabajo de Esteban CORRAL GARCÍA, Ordenanzas de los concejos castellanos. Formación, contenido y manifestaciones (siglos XIII-XVIII), Burgos, 1988.

10 José Antonio MARTÍn FUERTES, Los libros de acuerdos del concejo de Astorga (s. XV), "La ciudad hispánica durante los siglos XIII al XVI", I, Madrid, Universidad Complutense, 1985, pp. 597-616; María Josefa PAREJO DELGADO, Las actas capitulares en el estudio del concejo bajomedieval: Úbeda, "Andalucía entre Oriente y Occidente (1236-1492). Actas del V Coloquio de Historia Medieval de Andalucía», Córdoba, Diputación Provincial, 1988, pp. 515-525; Serafín de TAPIA, La documentación fiscal concejil en el siglo XVI. Un instrumento imprescindible para la bistoria social, "Los archivos y la investigación», Avila, 1987, pp. 49-70; Paulina RUFO YSERN, Los Reyes Católicos y la problemática municipal andaluza a través del Registro General del Sello (1474-1480), "Andalucía entre Oriente y Occidente», cit, pp. 503-514.

1 Inicialmente publicada como artículo en el "Anuario de Historia del Derecho Español», II (1925), con posterioridad se han hecho varias reediciones como libro por el Servicio de Publicaciones de la Universidad de Sevilla. 
distintas instituciones relacionadas con sus haciendas, otros van más allá, al conjugarlo con el político, social o económico. En el primer grupo se encontraría la obra de Gibert sobre Madrid, pionera en este tipo de estudios, no tanto por el tema en sí, como por el tratamiento y enfoque, ya que existen otros trabajos anteriores de la misma naturaleza ${ }^{12}$. En el segundo grupo se encuadraría, en parte, la citada obra de Carande, así como las de Ruiz Povedano y Cruces sobre Málaga, o la de Guerrero Navarrete sobre Burgos, entre otras ${ }^{13}$.

Más numeroso es el grupo integrado por monografías de historia local en las que se incluye un capítulo o se le dedican algunos apartados de un capítulo al tema. En este caso, se analizan fundamentalmente los siguientes aspectos: en primer lugar los órganos concejiles relacionados con la gestión económica, así como los mecanismos empleados en dicha gestión; en segundo lugar, la formación de la hacienda y descripción de los conceptos de ingreso, así como de los gastos; si se ha conservado la documentación contable, se aportan cifras parciales o de conjunto de tales ingresos, y en el mejor de los casos se hace un balance de ingresos y gastos; en fin, más excepcionalmente, se entra en el análisis de políticas fiscales. La serie se inició con la tesis de Manuel González Jiménez sobre Carmona, que aparece en 1973. En la actualidad rara es la monografía que trata de ofrecer una visión más o menos general de una ciudad

12 Nicolás TeNORIO CEREZO, El concejo de Sevilla. Estudio de la organización políticosocial de la ciudad, Sevilla, 1901; Rafael GIBERT Y SÁNCHEZ DE LA VEGA, El concejo de Madrid. Su organización en los siglos XII a XV, Madrid, Instituto de Estudios de Administración Local, 1949; María Isabel FALCÓN PÉREZ, La organización municipal de Zaragoza en el siglo XV, Zaragoza, Universidad, 1978; Juan Antonio BONACHIA HERNANDO, El concejo de Burgos en la Baja Edad Media (1345-1426), Valladolid, Universidad, 1978; A. Carlos MERCHAN FERNÁNDEZ, El gobierno municipal en Extremadura durante la Baja Edad Media, Cáceres, Universidad de Extremadura, 1984; Joaquín CERDÁ RUIZ-FUNES, Estudios sobre instituciones jurídicas medievales de Murcia y su reino, Murcia, Academia Alfonso X el Sabio, 1987.

13. José María RuIz Povedano, El primer gobierno municipal de Málaga (14891495), Granada, Universidad de Granada, Ayuntamiento de Málaga, 1991; Esther CRUCES BLANCO, La configuración político-administrativa del concejo de Málaga. Regidores, jurados y clanes urbanos (1495-1516), tesis doctoral inédita; Yolanda GUERRERO NAVARRETE, Organización y gobierno de Burgos durante el reinado de Enrique IV de Castilla (1453-1476), Madrid, Universidad Autónoma, 1986; Juan ABELlÁN PÉREZ, El concejo murciano de junio de 1429 a junio de 1430. Su estructura, "Miscelánea Medieval Murciana», V (1980), pp. 121-158. En relación con memorias de licenciatura y tesis doctorales que están inéditas, aunque no las he podido consultar todas, citaré aquellas de que tengo noticias, con el fin de hacer lo más completo posible el presente elenco bibliográfico. 
que no toca todos o casi todos estos aspectos, siempre que se disponga de la documentación idónea ${ }^{14}$.

Si de las historias de ciudades pasamos a los estudios específicos hay que aludir inicialmente a una serie de trabajos en los que se ofrecen unos planteamientos generales sobre cuestiones más o menos concretas, como es el tema de

${ }_{14}$ Corona de Aragón: Eliseo Vidal Beltran, Valencia en la época de Juan I, Valencia, Universidad, 1974; María Luisa Ledesma Rubio y María Isabel FALCón PÉREZ, Zaragoza en la Baja Edad Media, Zaragoza, Librería General, 1977.

Corona de Castilla: Margarita CuARTAs Ribero, Oviedo y el Principado de Asturias a fines de la Edad Media, Oviedo, Instituto de Estudios Asturianos, 1983; José Ramón Díaz de Durana, Vitoria a fines de la Edad Media. 1428-1476, Vitoria, Diputación Foral de Alava, 1984; Ernesto García FernANDEZ, Laguardia en la Baja Edad Media (1350-1516), Vitoria, Diputación Foral de Alava, 1985; Manuel GonZÁLEZ GARCíA, Salamanca en la Baja Edad Media, Salamanca, Universidad, 1982; Severiano HeRnándeZ VicenTe, El concejo de Benavente, Zamora, 1986; Carmelo LUIS LÓPEZ, La comunidad de villa y tierra de Piedrabita en el tránsito de la Edad Media a la Moderna, Avila, Institución Gran Duque de Alba, 1987; Asunción Esteban ReCiO, Palencia a fines de la Edad Media. Una ciudad de señorio episcopal, Valladolid, 1989; María Jesús FUENTE PÉREZ, La ciudad de Palencia en el siglo XV. Aportación al estudio de las ciudades castellanas en la Baja Edad Media, Madrid, Universidad Complutense, 1989; José María MONSALvo ANTÓN El sistema político concejil. El ejemplo del señorío medieval de Alba de Tormes y su concejo de villa y tierra, Salamanca, Universidad, 1988; Juan Carlos MARTIN CEA, El mundo rural castellano a fines de la Edad Media. El ejemplo de Paredes de Nava en el siglo XV, Valladolid, Consejería de Cultura y Turismo, 1991; María ASENJO GONZÁLEZ, Segovia, la ciudad y su tierra a fines del medievo, Segovia, Diputación y Ayuntamiento, 1986; Carlos EstePA, Juan A. BonACHIA HeRnANDO, Teófilo F. Ruiz, Hilario CAsado Alonso, Burgos en la Edad Media, Valladolid, Consejería de Educación y Cultura de Castilla y León, 1984; María Jesús SUÁrez ALVAREZ, La villa de Talavera y su tierra en la Edad Media (1369-1504), Oviedo, Universidad, 1982; Antonio Floriano Cumbreño, La villa de Cáceres, Cáceres, 1987; Luis Rafael Villegas DíAZ, Ciudad Real en la Edad Media. La ciudad y sus hombres (1255-1500), Ciudad Real, 1981; Julio VALDEÓN BARUQUE, Una ciudad castellana en la segunda mitad del siglo XIV: el ejemplo de Murcia, "Cuadernos de Historia», 3 (1969), pp. 211 -254; María de los Llanos MARTÍNEZ CARRILLO, Revolución urbana y autoridad monárquica en Murcia durante la Baja Edad Media (1395-1420), Murcia, Universidad, 1980; María Belén PiQueras García, Fiscalidad real y concejil en el reinado de Enrique IV: el ejemplo de Murcia (1462-1474), Cádiz, Universidad de Cádiz y Academia Alfonso X el Sabio de Murcia, 1988; Manuel GonZÁleZ JIMÉNEZ, El concejo de Carmona a fines de la Edad Media (1464-1523), Sevilla, Diputación Provincial, 1973; John EDWARDS, Christian Cordoba. The city and its region in the Late Middle Ages, Cambridge, Cambridge University Press, 1982; Antonio GonZÁLEZ GómEZ, Jerez de la Frontera en el siglo XV. Aspectos económicos, sociales y administrativos, tesis doctoral inédita. 
los de los orígenes o formación de las haciendas concejiles, ya sea con carácter general ", referidos a ciertas regiones o momentos ${ }^{16}$, o bien centrados en determinadas ciudades ". Otro grupo se ha preocupado por el análisis de los propios ${ }^{18} \mathrm{y}$ de los comunales, ligados a aquéllos en sus orígenes y utilizados en la etapa final como expediente para resolver problemas de déficit ${ }^{19}$.

Aparte de estos títulos, llama la atención la citada dispersión y atomización de los trabajos, tanto por lo que se refiere a su ámbito geográfico como al temporal, e incluso en lo relativo a su contenido. En unos casos, esta atomización es fruto del carácter excepcional de la documentación conservada, pero en otros parece claro que se trata de publicaciones coyunturales, sobre todo cuando sus autores no se han especializado en esta línea de investigación. Son frecuentes los trabajos sobre algún o algunos tipos de impuestos, sobre las cuentas de tal o cual año concreto, etc. Por todo ello, los he agrupado en tres apartados: estudios de una cierta amplitud temática, estudios sobre tipos de impuestos concretos y estudios de contabilidades.

a) En el apartado de estudios más generales abundan los artículos en los que se analizan tanto las instituciones municipales encargadas de la gestión

1s Isabel ÁlvareZ-Cienfuegos CAMPOS, Notas para el estudio de la formación de las baciendas municipales, "Homenaje a Don Ramón Carande», Madrid, 1963, pp. 3-19

16 Antonio COLLANTES DE TERÁN SÁNCHEZ. La formación de las haciendas locales en el Reino de Granada, «Estudios sobre Málaga y el Reino de Granada en el V Centenario de su conquista", Málaga, Diputación Provincial, 1988, pp. 185-197; Alfonso X y los Reyes Católicos: la formación de haciendas municipales, "En la España Medieval», 13 (1990), pp. 253-270.

17 Francisco Bejarano, Fundación de la hacienda municipal de Málaga por los Reyes Católicos, Málaga, 1951; María Birriel Salcedo, Notas sobre la bacienda municipal de Granada en el primer tercio del siglo XVI, "Chronica Nova», 10 (1979), pp. 123-140.

${ }^{18}$ I. Álvarez-Cienfuegos, Notas para el estudio cit.; Agustín Bermúdez AzNAR, Bienes concejiles de propios en la Castilla bajomedieval, "Actas del III Symposium de Historia de la Administración", Madrid, 1974, pp. 825-853; Luis MARTínEZ GarcíA, Los bienes de propios de la villa de Madrid en la Edad Media, memoria de licenciatura inédita. En otras obras, como en la de Veas Arteseros, se pueden encontrar también reflexiones sobre esta cuestión.

19 Este es un tema con una larga tradición historiográfica, que se remonta al pasado siglo con obras como la de Francisco CÁRDENAS, Ensayo sobre la bistoria de la propiedad territorial en España, II, Madrid, s. a., y en el actual las de Alejandro NiETO, Bienes comunales, Madrid, Editorial Revista de Derecho Privado, 1964; José MARTínez GijÓN y otros, Bienes urbanos de aprovechamiento comunal en los Derechos locales de Castilla y León, "Actas del III Symposium", cit., pp. 197-252; David E. VASSBERG, Tierra y sociedad en Castilla. Señores, "poderosos" y campesinos en la España del siglo XVI, Barcelona, Crítica, 1986; José Luis MARTíN MARTIN, Evolución de los bienes comunales en el siglo XV, "Studia Historica», VIII (1990), pp. 7-46. 
como la tipología de los ingresos y gastos, incluyendo las contabilidades. Como señalé más arriba, a la cabeza se encuentran los referidos a la ciudad de Murcia, llevados a cabo por diversos historiadores entre los que cabe destacar por el volumen de su producción a Denis Menjot ${ }^{20}$ y a María del Carmen Veas Arteseros ${ }^{21}$. Los restantes trabajos los agrupo por reinos ${ }^{22}$.

b) Entre los centrados en tributos concretos destaca la atención prestada a los impuestos directos en sus distintas formas y denominaciones (tallas, repartimientos, pedidos, derramas, pechos, etc.). En unos casos fueron una forma habitual de hacer frente a las necesidades de los concejos, sobre todo en la Corona de Aragón, y en especial en Cataluña, debido a la ausencia o escasa importancia de los bienes de propios. En menor medida en la de Castilla, en la que parece tratarse de un medio habitual hasta la formalización del sistema de propios como procedimiento ordinario de hacer frente a los gastos, y posteriormente un recurso extraordinario, ante las dificultades de los concejos para

${ }^{20}$ Fiscalidad y sociedad. Los murcianos y el impuesto en la Baja Edad Media, Academia Alfonso X el Sabio, Murcia, 1986, en la que se han recogido varios artículos editados en distintas revistas.

21 Fiscalidad concejil en la Murcia de fines del Medievo, Murcia, Universidad, 1991; La bacienda concejil murciana en el siglo XV (1423-1482), edic. microfichas, Murcia, Universidad, 1988. Otros autores que han trabajado sobre el tema son Juan Torres Fontes, La hacienda concejil de Murcia en el siglo XIV, "Anuario de Historia del Derecho Español», XXVI (1956), pp. 741-756; María de los Llanos MARTíneZ CARRILlO, Notas sobre la economía concejil murciana en el siglo XIV, «Anuario de Estudios Medievales», 17 (1987), pp. 289-298; Francisco CHACÓN JIMÉNEZ, Una contribución al estudio de las economías municipales en Castilla. La coyuntura económica concejil murciana en el período 1496-1517, "Miscelánea Medieval Murciana», III (1977), pp. 213-257.

22. Para la Corona de Castilla, Mercedes Borrero FernándeZ, Las haciendas de los concejos rurales sevillanos, "Actas del II Coloquio de Historia Medieval Andaluza», Sevilla, Diputación Provincial, 1982, pp. 67-80; Marina MARTín OJEDA, La bacienda concejil ecijana a fines de la Edad Media a través de las ordenanzas municipales, «Actas del I Congreso sobre Historia de Écija», I, Écija, 1988, pp. 367-381; María del Mar GARCía GuZMÁN, Rentas y bienes de propios del concejo de Garcimuñoz según sus ordenanzas de 1497, "Actas del Congreso de Historia del Señorío de Villena», Albacete, 1979; Margarita CANTERA MONTENEGRO, La bacienda concejil y la vida económica de Logroño en tiempos de los Reyes Católicos (1475-1495), "Anuario de Estudioas Medievales», 17 (1987), pp. 511-524; Julio A. PARDOS MARTÍNEZ, La organización financiera del concejo de Burgos, 1431-1445, Valladolid, memoria de licenciatura inédita. Para la Corona de Aragón, Bonifacio Palacios MARTín y M. ${ }^{a}$ Isabel FALCÓN PÉREZ, La hacienda municipal de Zaragoza a mediados del siglo XV (1440-1472), «Historia de la Hacienda Española», cit., pp. 539-606; Max TURUll RUBINAT, Configuració jurídica del municipi baix-medieval. Règim municipal: fiscalitat a Cervera entre 1182-1430, Fundació Noguera, 1990. Para el Reino de Navarra, Juan CARRASCO PÉREZ, Sobre la hacienda municipal de Tudela a fines de la Edad Media (1480-1521), "Historia de la Hacienda Española», cit., pp. 127-169. 
cubrir sus necesidades con aquellos. En algunos de los trabajos se presta atención a los procedimientos para fijar las cantidades que cada contribuyente debe pagar, así como a los mecanismos de recaudación ${ }^{23}$. Para éstos, así como para los aspectos técnicos de los repartimientos se puede consultar la bibliografía relativa a los percibidos por los reyes, ya que fueron similares.

Las sisas o imposiciones constituyen otro ámbito muy importante de la fiscalidad bajomedieval. Se presentan con unas características bastante similares a los impuestos directos, pues mientras en Cataluña y, en menor medida, en los otros reinos de la Corona de Aragón, es una de las fórmulas habituales de conseguir recursos, en la de Castilla fue, salvo excepciones, un impuesto extraordinario, aunque de creciente generalización a lo targo del siglo XV. La cada vez mayor importancia de las sisas está también en relación con un retroceso de los impuestos directos. En este sentido hay que señalar que van a ser frecuentes los debates en los cabildos a la hora de elegir entre una u otra forma de hacer frente a gastos extraordinarios. Además, en numerosos concejos de la meseta castellana, a través de la aprobación o asentimiento a decisiones ya tomadas se va a posibilitar un cierto grado de participación de los vecinos. Por todo esto, es rara la obra en la que se analice la hacienda o la fiscalidad de una ciudad en la que no se dedique un comentario o varias páginas a las sisas. Aparte de éllas, hay que citar varios trabajos específicos ${ }^{24}$.

Por lo que se refiere a otros estudios relativos a rentas ordinarias, predominan los que inciden sobre la circulación y comercialización de productos, ya que son los que acaban teniendo mayor peso, al menos en los principales centros urbanos ${ }^{25}$.

${ }^{23}$ En Mallorca ha estudiado la talla María BARCELÓ CRESPí, Ciutat de Mallorca en el trànsit a la modernitat, Palma de Mallorca, Institut d'Estudis Baleàrics, 1988; Més sobre l'impost de tall (1450-1521), "Randa», 29 (1991), pp. 185-217; Sobre una talla de 1478, «Boletí de la Societat Arqueològica Luliana», 39 (1983), pp. 435-448. Para la talla en Navarra, la obra de Ricardo CIERVIDE MARTíneZ y José Angel SESMA MUÑOZ, Olite en el siglo XIII. Población, economía y sociedad de una villa navarra en plena Edad Media, Pamplona, Institución Príncipe de Viana, 1980. Para la Corona de Castilla están los trabajos de María ASENJO GONZÁlEZ, Repartimiento de "pechos» en Tierra de Segovia, "La ciudad hispánica", cit., pp. 717-744; Estructura y forma de una bacienda local a fines del siglo XV: la ciudad de Soria y su tierra, "Celtiberia», 65 (1983), pp. 111-124; María de los Llanos MARTíneZ CARRILlO, El padrón de cuantiosos murcianos de 1374, «Miscelánea Medieval Murciana», XI (1984), pp. 237-260; y las páginas que les dedican J. M." MONSALVO, El sistema político concejil, cit.; y J.C. MARTÍN CEA, El mundo rural castellano, cit., entre otros.

${ }^{24}$ María del Carmen VEAS ARTESEROS, Notas sobre la renta de la sisa en Murcia (siglo XV), «Mayurca», 22 (1989), II, pp. 655-664; Jean BROUSSOLLE, Les impositions municipales de Barcelone de 1318 à 1462, "Estudios de Historia Moderna», 5 (1955), pp. 3-164.

25 Julio A. PARDOS MARTínEZ, La renta de la "alcabala vieja, portazgo y barra» del 
Dentro del apartado de ingresos extraordinarios hay varios trabajos dedicados a la deuda pública municipal en Barcelona, donde tanta importancia adquirieron ${ }^{26}$, Zaragoza, Mallorca o Tudela ${ }^{27}$. En Castilla, hasta el presente, el único caso conocido es el de Burgos ${ }^{28}$. Tanto si se acudía a ésta como si no, el recurso al crédito fue otro expediente habitual de los concejos para hacer frente a dificultades por lo general de liquidez, y en algunas de las obras ya mencionadas, al analizar los ingresos extraordinarios, se incluye el crédito entre ellos ${ }^{29}$.

c) El tercer grupo de trabajos está formado por los que han prestado una atención especial a la publicación y estudio de datos contables. En muchos casos se trata de documentos excepcionales, al ser los únicos que se han conservado para el período del que me vengo ocupando, aunque no siempre es así. En otros, se trata de series más largas que abarcan varias décadas ${ }^{30}$. Además, en

concejo de Burgos durante el siglo XV (1429-1503), «Historia de la Hacienda Española», cit., pp. 607-680; Eloy BENITO RUANO, La alcabalina, "León y su historia», CSIC, 1969, pp. 283-300; M. ${ }^{2}$ P. GIL GARCíA, Portazgo y almotacenazgo en La Roda de Albacete a fines de la Edad Media, "Actas del Congreso de Historia del Señorío de Villena", Albacete, 1979; Carmen ARGENTE DEL CASTILLO OCAÑA, La ganaderia medieval andaluza, siglos XIII-XVI (Reinos de Jaén y Córdoba), 2 vols., Jaén, Diputación Provincial, 1991; César GoNZÁlez MínGUeZ, El portazgo en la Edad Media. Aproximación a su estudio en la Corona de Castilla, Leioa, Universidad del País Vasco, 1989, que estuvo precedido de una serie de trabajos sobre el tema.

${ }^{26}$ Y. ROUSTIT, La consolidation de la dette publique à Barcelone au milieu du XIVe siècle, "Estudios de Historia Moderna», IV (1954), pp. 15-156; Arcadi GARCía SANZ, El censal, "Boletín de la Sociedad Castellonense de Cultura», 37, pp. 281-305.

${ }_{27}$ B. Palacios y M." I. Falcón, La hacienda municipal de Zaragoza, cit.; Pablo Cateura Bennasser, Política y finanzas del reino de Mallorca bajo Pedro IV de Aragón, Palma de Mallorca, Institut d'Estudis Baleàrics, 1982; J. CARRAsCO, ob. cit.

${ }^{28}$ Julio A. PARDOS MARTÍNEZ, Constitución política y comunidad en Burgos a fines del siglo XV (Reflexiones en torno a un documento de 1475), "La ciudad hispánica», cit., I, pp. 545-580; Hacienda municipal y constitución de rentas: "censos" y deuda del concejo de Burgos, 1476-1510 ca., "Anuario de Historia del Derecho Español», LIV (1984), pp. 599-613; Yolanda GueRRero NAVARRETE, Organización y gobierno, cit.

${ }^{29}$ Una visión de conjunto sobre el crédito en Miguel Angel Ladero, Formas de crédito en los reinos españoles. Siglos XII al XV, "9th Congress of the International Economic History Association", Berne, 1986.

${ }^{30}$ María Ángeles MONTURiol GonZÁlez, Estructura y evolución del gasto en la bacienda municipal de Madrid: último tercio del siglo XV, «En la España Medieval», IV (1984), pp. 653-692; El ingreso en la hacienda municipal de Madrid: su estructura y evolución (1464-1497), «La ciudad hispánica», cit., II, pp. 1027-1057; L. CAMÓs CABRUJA, Un libro de cuentas municipales del siglo XIV, "Divulgación Histórica», III, Barcelona, 1947, pp. 153-156; Eloy BENITO RuANO, Un cuaderno de cuentas del Ayuntamiento de Avilés (14771478), «Asturiensia Medievalia», 4 (1981), pp. 217-235; Angel Luis MOlinA MOlinA, La 
bastantes de las monografías sobre ciudades y en otros artículos que ya he citado se pueden encontrar estudios de este tipo. Aunque en todos los casos existen lagunas, las series más largas son las de Burgos, Murcia y Sevilla, que se inician a fines del siglo XIV; y más corta la de Piedrahita, que arranca de 1413. Las restantes que se han conservado corresponden, en general, a la segunda mitad del siglo XV. Un rasgo bastante generalizado que se deduce de estas contabilidades y de la interpretación de otros datos, como la proliferación de impuestos extraordinarios, es la frecuente incapacidad de los concejos para hacer frente a sus necesidades con los recursos ordinarios, los cuales se iban, en su mayor parte, en pagar la nómina de oficiales, funcionarios y servidores. Aparte de las obras públicas y de los pleitos, uno de los motivos de los fuertes desequilibrios fueron los elevados salarios de los corregidores, que los reyes obligaron a pagar a las ciudades.

Para terminar, hay que aludir a una serie de artículos en los que se tocan aspectos puntuales, o que inciden de alguna manera en la hacienda o fiscalidad municipales ", $\mathrm{y}$ a otros que sin estar directamente relacionados con ellas pueden aportar datos al estudiar aspectos de la vida urbana que, de alguna manera, tocan a la hacienda. En unos casos se puede tratar de obras públicas, que lo normal es que exijan una financiación especial, pues ya he dicho que los recursos ordinarios no son suficientes para estas empresas de envergadura ${ }^{32}$; en

economía concejil murciana en 1479-1480, «Miscelánea Medieval Murciana», I (1973), pp. 111-138; María del Carmen MELENDRERAS GIMENO, Gastos e ingresos del concejo murciano en 1459-1460, «Miscelánea Medieval Murciana», I (1973), pp. 139-174; María Luisa LEDESMA RUBIO, La hacienda municipal de Zaragoza en el año 1442, "Historiografía Medieval. Homenaje al Prof. Angel Canellas LÓPEZ», Zaragoza, 1969, pp. 671-687; Miguel Angel LADERO QUESADA, Los propios de Sevilla (1486-1502), "Homenaje a César Albiñana", Madrid, 1987, pp. 1425-1455; A. FURIÓ-FERRAN GARCÍA, La economía municipal de Alzira a fines del siglo XIV, según un libro de cuentas de 1380-1381, "La ciudad hispánica», cit., II, pp. 1611-1633; Angel J. MARTín DUQUE, Cuentas del burgo de San Cernin de Pamplona. Año 1244, Pamplona, 1976.

"Gabriel LlOMPART, La nómina municipal de la ciudad de Mallorca en 1374, "Mayurqa», 22 (1989), I, pp. 367-372; María de los Llanos MARTíneZ CARRILlo, Las pujas de quinto en los arrenda mientos de rentas de la segunda mitad del siglo XIV, "Miscelánea Medieval Murciana», XII (1985), pp. 9-26; César GonZÁlez MíngueZ, Algunos conflictos entre los mercaderes vitorianos y los arrendadores de la renta de barra y portazgo de Burgos en el siglo XV, «La ciudad de Burgos. Actas del Congreso de Historia de Burgos», Burgos, Consejería de Cultura y Turismo, 1985, pp. 201-216.

32 Pablo CATEURa BenNASSER, La infraestructura comercial de Mallorca en la segunda mitad del siglo XIV, "Libera Università Trapani», 18 (1988), pp. 29-40; Isidoro GoNZÁLEZ GALLEGO, Las murallas y los puentes de León en el siglo XIV, "León y su historia», IV (1977), pp. 365-411. 
otros serán las exigencias de la Corona "; en otros, las repercusiones de hechos extraordinarios, ya sea la implantación de la Inquisición o la llegada de una epidemia ${ }^{34}$; también en estudios de contenido económico es posible hallar alguna información ${ }^{35}$.

Otro ámbito temático es el de los oficios concejiles encargados de la gestión y control de la hacienda. La abundancia de fuentes de tipo jurídico ha posibilitado que uno de los aspectos al que se ha prestado una mayor atención en términos relativos sea el de la organización institucional. En este sentido, gran parte de las obras que ofrecen visiones de conjunto dedican algunas páginas a un análisis de todos o de algunos de los órganos de gestión: clavarios, mayordomos, jurados, procuradores, jurados clavarios, etc. En la actualidad la única obra de conjunto es la de Esteban Corral ${ }^{36}$, en la que realiza un estudio jurídico de la institución; las restantes se refieren a ciudades concretas ${ }^{37}$. En relación con los análisis exclusivamente institucionalistas habría que advertir que corren el riesgo de ofrecer una imagen poco real, como otras fuentes se encargan de poner de manifiesto, y se puede comprobar en varios trabajos. A lo largo del siglo XV se observan importantes alteraciones de la legalidad, en parte motivadas por el intervencionismo de los reyes, el desgobierno municipal o las crecientes dificultades financieras de los concejos. También resalta el carácter multiforme de la figura del mayordomo o clavario en el conjunto de la geografía hispana, sobre todo por lo que se refiere a su extracción social o formación técnica. Mientras en algunas ciudades y momentos son miembros de la oligarquía, en otras son caballeros, burgueses, o se exige que sean pecheros.

A diferencia de la atención prestada a los órganos de gestión, es mucho

"Francisco Sevillano Colom, Préstamos de la ciudad de Valencia a los reyes Alfonso $V$ y Juan II (1426-1472), "Estudios Medievales», I, Valencia, 1951, pp. 85-131; Las empresas nacionales de los Reyes Católicos y la aportación económica de la ciudad de Valencia, «Hispania», XIV (1954), pp. 511-623.

${ }^{34}$ Juan de M. CARriazo ARROQUIA, La Inquisición y las rentas de Sevilla, "Homenaje a don Ramón Carande», II, pp. 95-112; Agustín RuBIO, Peste Negra, crisis y comportamientos sociales en la España del siglo XIV. La ciudad de Valencia (1348-1401), Granada, Universidad, 1979.

"Elisa C. de Santos CanalejO, La vida económica de Plasencia en el siglo XV, «En la España Medieval», III (1982), pp. 553-593.

${ }^{36}$ El mayordomo de concejo en la Corona de Castilla (s. XIII-s. XVIII). El Consultor de los Ayuntamientos y de los Juzgados, Madrid, 1991.

${ }^{37} \mathrm{M}^{4}$. C. VEAS ARTESEROS, Fiscalidad concejil, cit.; Las finanzas del concejo murciano en el siglo XV: el mayordomo, "Homenaje al Profesor Juan Torres Fontes», II, Murcia, 1987, pp. 1725-1739; Antonio COllantes DE TERÁN SÁNCHEZ, El mayordomo del concejo de Sevilla en el siglo XV. Memoria de licenciatura inédita. 
menor la otorgada a los de control: contadores, mestres racionales, etc. ${ }^{38}$. También existen intentos de aproximación a otros colectivos que jugaron un papel fundamental en la recaudación de las distintas rentas concejiles dada la generalización del sistema de arriendo. Me refiero a los arrendadores, cogedores, fiadores, etc. Aparte de algún trabajo específico, o en el que se alude a la participación de ciertos colectivos en estas actividades ${ }^{39}$, en distintas obras de las ya mencionadas se le presta atención y se publican algunas relaciones de arrendatarios ${ }^{40}$. El estudio de estos colectivos constituiría una vía de aproximación a la existencia de lo que se podrían denominar grupos burgueses en los centros urbanos hispanos.

Para terminar hay que referirse a una perspectiva clave de cualquier estudio sobre hacienda y fiscalidad: la política, en su doble vertiente de política hacendística o fiscal y de análisis político de la fiscalidad. En el primer caso, por ejemplo, la transformación de bienes comunales en propios, o la ya mencionada opción entre repartimientos y sisas. Si se trata de repartimientos, qué criterios se emplean para evaluar la capacidad contributiva de los vecinos, cómo se establecen los baremos ${ }^{41}$. Por otro lado, como también he indicado antes, será una vía a través de la cual, en algunos centros urbanos, el común podrá hacer oir su voz o adquirir un cierto protagonismo frente a las oligarquías. Si se echan imposiciones o sisas, sobre qué productos y con qué condiciones.

Desde la perspectiva de un análisis político de la fiscalidad hay cuatro cuestiones que aparecen en los trabajos hasta ahora reseñados:

a) el de los orígenes de las haciendas y sobre todo de la fiscalidad concejil en

${ }^{38}$ Jesús LALINDE ABADÍA, Contabilidad e intervención en el reino aragonés, «Itinerario Histórico de la Intervención General del Estado», Madrid, Instituto de Estudios Fiscales, 1976, pp. 39-55.

${ }_{39}$ Antonio Collantes DE TERÁN SÁNCHeZ, Los fiadores en la bacienda concejil sevillana bajomedieval, "Mayurqa», 22 (1989), I, pp. 191-198; Angel Luis MolinA MoLINA, Mercaderes genoveses en Murcia durante la época de los Reyes Católicos, "Miscelánea Medieval Murciana», II (1976), pp. 277-312.

40 Y. Guerrero, Organización y gobierno de Burgos, cit.; M.a B. PIQUERAS, Fiscalidad real y concejil, cit.; D. MENJOT, Fiscalidad y sociedad, cit.; M." C. VEAS, Fiscalidad concejil, cit.; J.A. PARDOS, La renta de la "alcabala vieja", cit.; J. BROUSSOLLE, Les impositions, cit.; M." A. MONTURIOL, Estructura y evolución del gasto, cit.; A.L. MOLINA, La economia concejil, cit.; M." C. MelendRERAS, Gastos e ingresos, cit.

${ }^{41} \mathrm{~J} . \mathrm{M}^{2}$. MONSAlvo, El sistema político, cit.; J.C. MARTín CEA, El mundo rural, cit. 
relación con la hacienda y la fiscalidad de las respectivas monarquías. Aquí encontramos tanto estudios desde plateamientos jurídicos como políticos, en parte girando en torno a los propios ${ }^{42}$.

b) la relación entre autonomía económica y autonomía política de las ciudades y villas, tanto en el ámbito realengo como en el señorial. En este sentido, son frecuentes las afirmaciones sobre la importancia que tuvo la implantación de los corregidores en la Corona de Castilla o la incapacidad de los concejos para crear nuevos impuestos ${ }^{43}$. Entre los ejemplos concretos de intervención directa de la corona se encuentra el de Mallorca ${ }^{44}$.

c) en parte vinculado con el punto anterior, el papel de los concejos como instrumentos de la hacienda de la monarquía o de los señores respectivos. Aquí se entra en un tema en el que creo que aun no están demasiado claras las cosas. En concreto, las fronteras entre los dos ámbitos hacendísticos.

El hecho de que en los dos ámbitos, el del concejo y el de la monarquía o señor, se empleen similares procedimientos de recaudación, y no solo ésto, sino que además sea el concejo el encargado de gestionar dicha recaudación en nombre de la corona o del señor ¿no puede llevar a confundir los dos planos, y que se consideren como impuestos o ingresos concejiles lo que no son tales? De hecho, en algunos de los trabajos aquí reseñados se han analizado algunas sisas o derramas como formando parte de la respectiva hacienda municipal cuando no parece que sean tales, sino realengas o señoriales.

En los últimos años han visto la luz bastantes trabajos en los que se profundiza en las relaciones entre las ciudades y la monarquía a través del papel jugado por aquéllas en la contribución y gestión de los recursos requeridos para hacer frente a las necesidades de las coronas ${ }^{43}$. A través de ellos se ha puesto de manifiesto cómo los centros urbanos fueron utilizados por los reyes como instrumentos, agentes o gestores de la hacienda regia. Esto no quiere decir que necesariamente dicha actuación se confunda con la gestión de la hacienda concejil respectiva. Con otras palabras, que la hacienda concejil se vea necesa-

12 Ver nota 18. También J. A. PARDOS, La renta de la "alcabala vieja", cit.

43 Aparte de las consideraciones que se hacen en numerosas obras ya mencionadas, cabría citar el trabajo de José F. LÓPEZ BONET, La pràctica fiscal a la Mallorca de la Baixa Edat Mitjana (segles XIII-XVI), «Randa», 29 (1991), pp. 13-36.

14 P. Cateura, Política y finanzas, cit.

45 Por lo que se refiere a Castilla, mientras que M. A. Ladero lo hace desde la perspectiva de los órganos centrales de la administración, otros historiadores lo realizan desde la perspectiva urbana. Por ejemplo, T. F. Ruiz y Y. Guerrero Navarrete para Burgos; D. Menjot y M." Ll. Martínez Carrillo para Murcia, por citar las dos ciudades en las que más atención se ha prestado a este tema. En la Corona de Aragón A. Sesma Muñoz, M. Sánchez Martínez, T. de Montagut, Ch. Guilleré, entre otros, también en estos casos desde la perspectiva de las instituciones centrales. 
riamente afectada por esta función. Una cosa es que el concejo sea un gestor, más concretamente un recaudador de ingresos de la corona, o de los señores, en su caso, y otra muy distinta que la hacienda municipal contribuya por vía ordinaria o extraordinaria a los ingresos de dicha corona o del señor correspondiente. Por ejemplo, tanto los pedidos castellanos como, a fines del siglo XV, la contribución de la Hermandad no siempre fueron recaudados por vía directa, sino mediante la implantación de sisas de cuya recaudación se encargaba el concejo. ¿Se pueden considerar como parte de la hacienda concejil o, por el contrario, se trataba de recursos extraordinarios de la corona gestionados por el concejo?

Con esto no quiero decir que las exigencias de la monarquía no puedan repercutir en la hacienda concejil. En los ejemplos antes citados, si dichas haciendas actuaban como responsables subsidiarias, o bien porque ciertos gastos que se derivasen de dicha recaudación corriesen por cuenta de los concejos. El otro caso sería el de las contribuciones, a veces en forma de préstamos, de los concejos de la Corona de Aragón a los reyes ${ }^{40}$. De todas formas, en la actualidad, hay que admitir un cierto grado de indefinición en las fronteras entre ambas haciendas, y es una cuestión en la que es preciso profundizar ${ }^{4}$.

d) la hacienda y la fiscalidad como instrumentos de afirmación y de conservación del papel de las oligarquías. Las posturas adoptadas ante distintos mecanismos de presión fiscal, a la hora de decidir sobre qué productos son objeto de gravamen y en qué proporción, quiénes quedan exentos, etc., Por ejemplo, el que en Madrid se distingan entre sisas de pecheros y sisas de privilegiados ${ }^{48}$. En algunos trabajos se observa cómo la gestión de la hacienda concejil y los abusos cometidos por la oligarquía constituyen argumentos de tensiones sociales o políticas ${ }^{49}$. En otros se pone el énfasis en el protagonismo

46 F. Sevillano Coløm, Préstamos de la ciudad, cit, pp. 85-131; Las empresas nacionales, pp. 511-623; J. SOBREQUÉS CALLICÓ, Contribució econòmica del municipi de Barcelona a l'empresa de recuperació del Regne de Mallorca per Pere el Cerimoniós (1343-1349), "VIII Congreso de Historia de la Corona de Aragón. La Corona de Aragón en el siglo XIV», III, Valencia, 1973, pp. 291-302.

4) Un ejemplo sería el pago de una multa a los prestamistas burgaleses, de la que se hace cargo el concejo (Teófilo F. RUIZ, Una nota sobre la estructura y relaciones fiscales del Burgos bajomedieval, "En la España Medieval», III (1982), pp. 387-397.

48 M." A. MONTURIOI., El ingreso en la bacienda, cit.

4) Carmen BATLLE, La crisis social y económica de Barcelona a mediados del siglo XV, 2 vols., Barcelona, CSIC, 1973; Aurelio PRETEl MARÍN, La comunidad y república de Chinchilla (1488-1520). Evolución de un modelo de organización de la oposición popular al poder patricio, Albacete, Instituto de Estudios Albacetenses, 1989; Fernando MAZO ROMERO, Problemas internos y tensiones sociales en el municipio cordobés durante la primera mitad del siglo 
desempeñado por los pecheros a la hora de aprobar y repartir determinados impuestos, a través de los estudios recientes sobre el tema de la "comunidad" en centros urbanos de la meseta castellana ". Otra variante del análisis de las relaciones entre oligarquía y pecheros a través de esta fiscalidad es la que afecta al papel asignado a las villas y aldeas de la tierra por las oligarquías urbanas y las tensiones entre las dos partes".

\section{RÉSUMÉ}

Le but de cet article est de présenter la bibliographie de la fiscalité et des biens municipaux pendant les règnes espagnols du Moyen Age. Ce travail se justifie par le manque d'ouvrages de synthèse, la multitude de travaux qui ont vu le jour ces dernières années et leur dispersion.

Le premier paragraphe reprend la publication des sources.

Dans le coeur même de l'ouvrage on présente, en premier lieu, les histoires urbaines, leur dédiant quelques chapitres ou paragraphes, faisant la distinction entre celles qui envisagent la perspective institutionnaliste ou celles dont les visions sont plus ou moins générales. Puis suivent les travaux spécifiques. On traite en premier lieu de ceux qui offrent une analyse plus complète, aussi bien sur le plan des institutions comme des recours et dépenses, pour passer ensuite à un paragraphe traitant d'aspects plus concrets, entre autres ceux centrés sur les comptabilités, ceux traitant de certains types de revenus ou même des institutions elles-mêmes.

Ou conclue par des références à des travaux qui portent leur attention sur les aspects politiques de la fiscalité.

XV, «Andalucía Medieval: nuevos estudios», Córdoba, Monte de Piedad y Caja de Ahorros de Córdoba, 1979, pp. 175-210; María Dolores GARCía Oliva, Organización económica y social del concejo de Cáceres y su tierra en la Baja Edad Media, Cáceres, Institución Cultural El Brocense, 1990; Oligarquía y finanzas municipales en Cáceres durante el reinado de los Reyes Católicos, «Norba», 2 (1981), pp. 181-192.

5) Entre los que tocan esta cuestión se encuentran Y. GuERRERO, Organización y gobierno de Burgos, cit.; J. M. ${ }^{a}$ MONSALVO, El sistema político, cit.; M. ${ }^{a}$ ASENJO, Estructuras y formas de una hacienda local, cit.; M." A. MONTURIOL, Estructura y evolución del gasto, cit.

"Como ejemplos de dichos análisis, referidos en este caso a la meseta castellana, se encuentran los citados en la nota precedente, a los que se añadiría el trabajo de Jesús MARTÍnez MORO, La Tierra de la Comunidad de Segovia. Un proyecto señorial urbano (1088-1500), Valladolid, Universidad, 1985. Un ejemplo con connotaciones específicas es el del conflicto entre la ciudad de Palma y las villas foráneas en Mallorca (P. CATEURA, Política $y$ finanzas, cit.). 


\section{SUMMARY}

The purpose of this article is to present a bibliography of the tax system and the municipal possessions during the Spanish reigns of the Middle Ages. There are very few concise books on this topic but a great quantity of works have been written and divulged in the last few years.

The first paragraph lists the sources.

As far as the article itself is concerned, the first topic treated in several paragraphs is urban history, making the difference between those that have an institutionalist or a more general point of view. After this, specific works are treated: first of all, those that offer a more complete analysis, with regard to institutions or expenditures and receipts; and then, there is a paragraph about more precise aspects such as compatibilities, institutions or even some types of receipts.

We finally refer to works about political aspects of the tax system. 